\title{
Stepping Stones Triple P and Acceptance and Commitment Therapy for Parents of Children with Cerebral Palsy: Trial Protocol - CORRIGENDUM
}

\author{
Koa Whittingham, Matthew Sanders, Lynne McKinlay and Roslyn N. Boyd \\ doi: 10.1017/BrImp.2013.19, published by Cambridge University Press 22 August 2013
}

There was an error made in the Declaration of Interest statement included in the above published article. To ensure transparency in the research process the authors wish to change the present Declaration of Interest statement to the following. The Triple P-Positive Parenting Program is owned by the University of Queensland (UQ). The University through its main technology transfer company UniQuest Pty Limited, has licensed Triple P International Pty Ltd to disseminate the program worldwide. Royalties stemming from this dissemination activity are distributed in accordance with the University's intellectual property policy and flow to the Parenting and Family Support Centre, School of Psychology, UQ; Faculty of Health and Behavioral Sciences; and contributory authors. No author has any share or ownership in Triple P International Pty Ltd. Matthew Sanders is the founder and an author on various Triple $\mathrm{P}$ programs and a consultant to Triple P International.

\section{Reference}

Whittingham, K., Sanders, M., McKinlay, L., \& Boyd, R. N. (2013). Stepping Stones Triple P and Acceptance and Commitment Therapy for Parents of Children with Cerebral Palsy: Trial Protocol. Brain Impairment, 14(2), 270-280. doi: 10.1017/BrImp.2013.19 